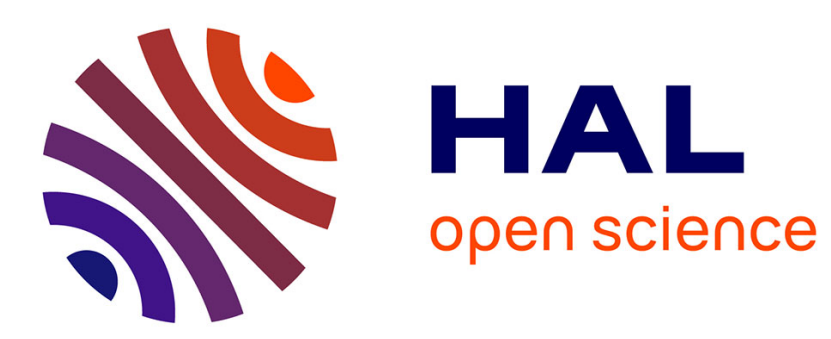

\title{
Do people contribute more to intra-temporal or inter-temporal public goods?
}

Gilles Grolleau, Angela Sutan, Radu Vranceanu

\section{To cite this version:}

Gilles Grolleau, Angela Sutan, Radu Vranceanu. Do people contribute more to intra-temporal or intertemporal public goods?. Research in Economics, 2016, 70 (1), pp.186-195. 10.1016/j.rie.2015.05.001 . hal-01594193

\section{HAL Id: hal-01594193 \\ https://hal.science/hal-01594193}

Submitted on 26 Sep 2017

HAL is a multi-disciplinary open access archive for the deposit and dissemination of scientific research documents, whether they are published or not. The documents may come from teaching and research institutions in France or abroad, or from public or private research centers.
L'archive ouverte pluridisciplinaire HAL, est destinée au dépôt et à la diffusion de documents scientifiques de niveau recherche, publiés ou non, émanant des établissements d'enseignement et de recherche français ou étrangers, des laboratoires publics ou privés. 


\section{Author's Accepted Manuscript}

Do People Contribute More to Intra-temporal or Inter-temporal Public Goods?

Gilles Grolleau, Angela Sutan, Radu Vranceanu

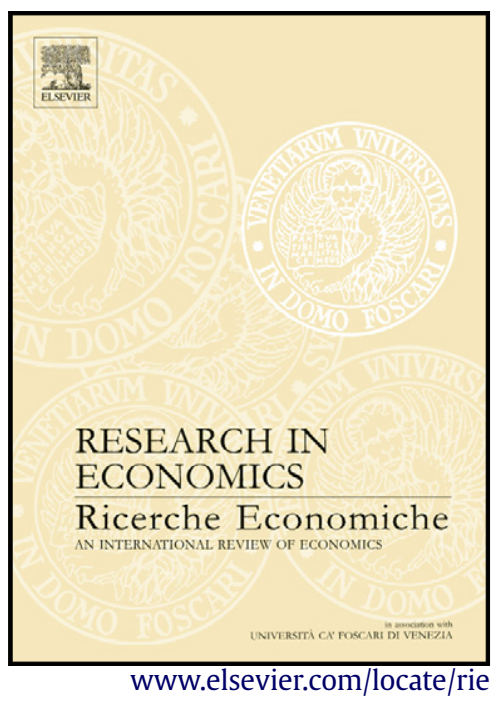

PII: $\quad$ S1090-9443(15)00029-0

DOI: $\quad$ http://dx.doi.org/10.1016/j.rie.2015.05.001

Reference: YREEC621

To appear in: Research in Economics

Received date: 26 October 2014

Accepted date: 18 May 2015

Cite this article as: Gilles Grolleau, Angela Sutan, Radu Vranceanu, Do People Contribute More to Intra-temporal or Inter-temporal Public Goods?, Research in Economics, http://dx.doi.org/10.1016/j.rie.2015.05.001

This is a PDF file of an unedited manuscript that has been accepted for publication. As a service to our customers we are providing this early version of the manuscript. The manuscript will undergo copyediting, typesetting, and review of the resulting galley proof before it is published in its final citable form. Please note that during the production process errors may be discovered which could affect the content, and all legal disclaimers that apply to the journal pertain. 


\title{
Do People Contribute More to Intra-temporal or Inter-temporal Public Goods?
}

\author{
Gilles Grolleau $^{(\mathrm{a}}$, Angela Sutan $^{(\mathrm{b}}$, Radu Vranceanu $^{(\mathrm{c}}$
}

$21 / 05 / 2015$

a) LAMETA, UMR 1135, and LESSAC, 2 place Viala, 34060 Montpellier, France. E-mail: grolleau@supagro.inra.fr.

b) LESSAC, ESC Dijon, and LAMETA, 29 rue Sambin, BP 50608, 21006 Dijon, France. E-mail: angelasutan@escdijon.eu.

c) Corresponding author. ESSEC Business School, and THEMA, 3 Av. Bernard Hirsch, PB 50105, 95021 Cergy, France, E-mail: vranceanu@essec.fr.

\begin{abstract}
We introduce a dynamic public goods game, where an individual's investment in the public good at a given round provides benefits to other individuals in the next round, and the individual himself benefits from investments in the public good made by his current group members in the previous round. Subjects turn out to be more generous in this intertemporal context, than in a standard public goods experiment where contributions and transfers are exchanged at the same period. Furthermore, when known, benefits from the past investment are positively related to the individual's current investment in the public good.
\end{abstract}

JEL Classification: C72, C92, H41.

Keywords: Dynamic public goods, Inter-temporal transfers, Voluntary contribution mechanism, Contribution vs. investment.

\section{Introduction}

Experimental economics has so far developed around a relatively small number of general purpose games, and a larger set of ad-hoc games with a more specific use. Among the fundamental games, the public good contribution game or simply the public goods (PG) game introduced in the seventies (see Bohm, 1972; Smith, 1979, 1980; Marwell and Ames, 1979), has emerged as the dominant model for analyzing the evolution of cooperation within groups of unrelated, anonymous individuals. The impressive success of the PG game is 
backed by its ability to parallel real life situations where people would be better-off if they collaborate, but they individually prefer to free ride, such as the common pool resource problem, the management of production externalities, the supply of public goods and services such as infrastructures (roads, bridges, parks) or national defense. ${ }^{1}$

In a typical public goods experiment, individuals are assigned to a group and are asked to sacrifice some direct individual utility by contributing to the public good. Individual contributions increase the utility of all other members of the group but cannot offset the sacrifice agreed to by the individual. Parameters are chosen such as when all group members contribute one unit of wealth to the PG, the individual's benefit, reflecting the sum of individual contributions, outweighs his sacrifice. The Nash-equilibrium of this game, as implemented by selfish, self-regarding agents, consists in all players making no contribution to the PG (Davis and Holt, 1993). ${ }^{2}$ Yet the utility of all group members would be the highest if they can coordinate their actions and make the highest contribution. ${ }^{3}$

One-shot public goods games were followed by analyses of finite horizon Repeated Public Goods (RPG) games, where individuals are asked to play the same game for several

${ }^{1}$ What makes the difference between a private and a public good is nonrivalry - several consumers can consume the good simultaneously, and nonexcludability - one cannot exclude from consumption an individual who does not pay the price.

${ }^{2}$ See Camerer and Fehr (2006) for a definition of the concept of "self-regarding" agent.

${ }^{3}$ Most experiments use the linear PG game and its voluntary contribution mechanism (VCE). A group of $N$ anonymous players having an individual endowment $W$ are asked to make a voluntary contribution $x$ to a common pool of money, with $x \in[0, \mathrm{~W}]$. Each gets back a constant percentage $m$ of the total contribution. The non-trivial situation corresponds to $m \in$ $[(1 / N) ; 1]$. In this case, a player does not gain enough to individually contribute one unit to the public good $(m<1)$, thus the Nash equilibrium is $x=0$ for all group members. If all contribute $W$, each will get $m N W$, which is obviously more than $W$ as obtained at the Nash equilibrium. 
rounds. Like in the one-period setting, in the standard RPG experiment, contributions are provided by, and benefits go to the same group members who play the game within the active round. Thus the decision sequence repeats itself identically from one round to another. In a finite horizon game with selfish self-regarding agents, free-riding at all rounds is also the subgame perfect equilibrium, since nothing can enforce cooperation at the last round. ${ }^{4}$ Note that in repeated games, decisions taken at the current round do not carry any material effect on the endowment or the marginal effect of contributing at latter periods, what makes their context “intra-temporal”. By contrast, in Dynamic Public Goods (DPG) games current decisions carry their effects on future endowments or utilities of other people, in a context that can be referred to as "inter-temporal". The main contribution of this paper lies in introducing a specific DPG and analyzing the behavior of the participants in this specific framework. But before moving to our experiment, it is worth introducing the main and robust results inferred from a sizeable body of literature on PG games, most often dominated by the linear version of the repeated public goods game.

Surveys of the experimental literature on the PG game by Davis and Holt (1993), Ledyard (1995), Holt (2006) and Chaudhuri (2011) acknowledge that when asked to play a standard linear RPG game, participants would contribute on average between $40 \%$ to $60 \%$ of their endowment in the first round, with wide variations between individuals, ranging from nothing, to $100 \%$ of their endowment. Zelmer (2003, p. 299) performed a meta-analysis of 349 PG experiments and found support that the "marginal per capita return, communication, constant group composition over the session ("partners"), positive framing, and the use of children as subjects had a positive and significant effect on the average level of contribution to the public good." Several studies point out that contributions tend to increase in larger groups (Isaac and Walker, 1988; Isaac et al. 1994; Carpenter, 2004). Other analyses

\footnotetext{
${ }^{4}$ In an infinitely repeated game, cooperation can be enforced by threats of not contributing to the public good.
} 
emphasize that enhanced anonymity is associated with lower voluntary contributions in PG games (Andreoni and Petrie, 2004; Alpizar et al., 2008, Hugh-Jones et al., 2011).

Many studies aim to explain why people do not follow the prediction of the theoretical model with rational, selfish agents by contributing nothing. Among the wide range of tested reasons, one can mention commitment (Bordignon, 1990), altruism (Smith et al., 1995; Andreoni, 1989, 1990) and reciprocity (Sugden, 1984). Croson (2007) performed a set of experiments to distinguish between these competing theories by testing their comparative statics predictions in a linear RPG setting and show that reciprocity theories dominate both theories of commitment and of altruism. Cooperation increases when introducing a social approval mechanism (Rege and Telle, 2004) of when the group had the opportunity to develop a social identity (Lankau et al., 2012). A relatively recent literature points out that a majority of individuals behave as "conditional cooperators", i.e. they tend to cooperate as long as the others cooperate, and reverse their behavior in the opposite case; thus they anchor their contribution to their beliefs about the contributions to be made by the other members of the group (inter alia, Keser and Van Winden, 2000; Fischbacher et al. 2001; Croson et al. 2005, Fischbacher and Gächter, 2010).

Another key finding, when the PG game is repeated several times with a clearly identified finite horizon, contributions start high, then tend to decline over time with an endgame effect where contributions get close to the zero amount predicted by the Nash equilibrium. Several scholars aim at understanding why contributions decline over the rounds. While it is beyond the purpose of our short paper to present all the relevant explanations, we can mention the "frustrated attempts at kindness" as indicated by Andreoni (1995) or initial confusion about the stakes and the game (Andreoni, 1995; Houser and Kurzban, 2002). In a more skeptical paper about the strengths of the experimental method, Levitt and List (2007) argue that subjects come to the lab with a cooperative view about the 
world, learn that that in the lab many subjects behave in a non-cooperative way, and then adapt their own behavior accordingly. Taking stock on an experiment building on the conditional cooperation theory, Fischbacher and Gächter (2010) argue that "the decline of cooperation can be driven by the fact that most people have a preference to contribute less than the others, rather than by their changing beliefs of others' contribution over time".

Andreoni (1988) has introduced an important methodological development in the analysis of RPG games. He asked participants to play a standard linear RPG game under two distinct treatments. In the "Partner" treatment, the composition of the group did not change for the ten round of the experiment. In the "Stranger" treatment, groups were rematched after each round among the total population participating to the experimental session. As mentioned by Andreoni (1988), in the second situation, the participants' ability to play strategically is much reduced, thus one would expect to observe lower contributions. Yet in his experiment contributions in the Stranger were significantly higher than in the Partner design. If a study by Palfrey and Prisbrey (1996) corroborated this result, other studies find the opposite one (Croson, 1996; Keser and Van Winden, 2000). The meta-analysis by Zelmer (2003) tends to support the result according to which contributions are higher in the Partner design than in the Stanger one. ${ }^{5}$

Moving one step further, several scholars have investigated what mechanisms can promote and sustain cooperation in a decentralized system of public goods provision. It has been shown that monetary sanctions or rewards (inter alia, Fehr and Gächter, 2000; Sefton et al. 2007; Carpenter, 2007; Nikiforakis and Normann, 2008), expressions of disapproval (Masclet et al., 2003) or advice giving (Bigoni and Suetens, 2012), can increase the level of

\footnotetext{
${ }^{5}$ This debate is probably interesting for this paper, as it points out that the PG games can sometimes produce results that challenge intuition, and thus require a significant number of replications before drawing a definitive conclusion.
} 
cooperation over rounds. In a highly cited paper, Fehr and Gächter (2000) analyzed a repeated PG, allowing for voluntary costly punishment of those who deviate from the prosocial strategy. They found that allowing for punishment allows restoring cooperation, and the effect is stronger in the Partner treatment than in the Stranger one. Note that their findings also depart from the predictions of an elementary model of collective action with selfish selfregarding agents, since individuals have all the incentive to free-ride on the provision of the sanction. The presence in the group of at least some "strong reciprocators" eager to bear the cost of punishing anti-social behavior might explain the emergence of cooperation (Camerer and Fehr, 2006).

By contrast with repeated public good games, the experimental literature on dynamic public good games is relatively scarce. As already mentioned, in a typical DPG game, subjects' decisions at a given round have an impact on endowments or utilities in future rounds. One notable exception is the paper by Cadigan et al. (2011) who developed an original two-stage DPG game to analyze the effect of transfers over time on the decision to contribute to the PG. In a first stage, subjects in a group of four can contribute to a public good and share the benefits of the contributions. Their endowment at the second stage is a linear function of gains earned at the first stage. At this stage, they must play again the public goods game. Cadigan et al. (2001) show that when the power of the carryover effect is increased (the amount transferred from one period to the other), the average contribution at the first stage increases, as if individuals display some form of inter-temporal altruism.

In this paper, we acknowledge that there are many every-day situations where an individual's participation to the PG will not benefit to the individuals who take decisions in the same time period with him, but to other individuals, at a deferred period in time. In turn, the same individual might benefit from the investment in public good made by other individuals in the previous period. The key difference between the standard "intra-temporal" 
and the "inter-temporal" context developed in this paper lays in the distinction between a "contribution" to a public good - with immediate effects on the well-being of the others, and "investment" in public good - with delayed effects on the well-being of the others.

For instance, tourists who travel in difficult-to-access areas (high altitude mountains, isolated beaches) that do not benefit from regular cleaning programs, often develop an environment-friendly, thoughtful and caring behavior, banning waste disposal and careless pollution of the natural environment. In particular, a positive response is recorded when the site was preserved by the former visitors. Another example, the Internet revolution led to the emergence of a myriad of e-commerce platforms, such as the emblematic firms Amazon and Tripadvisor if we consider only the subset of B-to-C relationships. One important innovation, that adds value to these trading platforms, is the option given to consumers to rate and post reviews about a product, service or supplier. Against all odds, consumers massively choose to provide unsolicited satisfaction feedback (Flanagin et al. 2014; Tsvetkova and Macy, 2014). No doubt, a key motivation driver behind this strong participation can be buyer-seller reciprocation, where satisfied / unsatisfied consumers want to reward / sanction the seller. Yet, one cannot rule out the "investment in public good" rationale where the consumer who benefited from the recommendation issued by a former client, will undertake a similar action to the benefit of future consumers. Since posting a review involves a cost for him in terms of time, this behavior reveals some form of inter-temporal altruism, or a subtler mechanism of cross-period, between-customers reciprocation.

This paper analyses this type of problem by means of a specific DPG game. In our experiment, individuals' contributions to the public good benefit not the current group, but to another group in the next round; in turn, individuals in the current round benefits from contributions to the public good made by another group of subjects in the previous round. The experiment is repeated ten times, hence it involves ten interconnected decisions. In order 
to limit the scope of reputation building and reciprocation, we use the Stranger design and rematch groups after each round. As a "natural" control representative of the "intra-temporal" context, we use a standard RPG game, with a similar Stranger design.

Given that the inter-temporal context loosens the already weak ties between the members of a group of anonymous subjects, we would predict a lower level of contribution in the inter-temporal context (DPG) than in the intra-temporal (RPG) context. Surprisingly, our main finding is that people contribute more to the public good in the inter-temporal context than in the intra-temporal context. Furthermore, in our data, an individual's contribution to the public good appears to be positively related to the benefit he receives from the past investment in public good by other individuals.

It must be emphasized that our analysis focuses on the behavior of an individual called to take several successive decisions in interaction with different groups of people. It is therefore not an analysis of "inter-generational" transfers, where choices of individuals within a well-defined group of people have consequences on another group that will form at the next period. $^{6}$

The paper is organized as follows. The next section introduces the main hypotheses and the design of the experiment. Section 3 presents the results. The last section discusses the main results and concludes.

\section{Main hypotheses and experimental design}

In our main inter-temporal context, at any round $t$, the subjects' endowment depends on the investment in the public good made by other individuals in $(t-1)$, and their contribution

\footnotetext{
${ }^{6}$ Other experiments have analyzed the dynamics of transfers among "generations", as pertaining to pension transfer schemes (Van der Heijden et al., 1998), the use of common pool resources (Fischer et al., 2004) or inter-generational investment advice (Chaudhuri et al., 2006).
} 
to the public good will benefit other players in $(t+1)$. In the control intra-temporal context, contributions and benefits are simultaneously shared among individuals of the group at any round $t$.

Such a deferred transfer mechanism might entail changes in subjects' behavior. All groups, even the anonymous ones, generate some form of weak ties that might support cooperation. In particular, in an experiment run with students from the same school, even if anonymity is guaranteed, they share common values and beliefs and have a similar identity. As argued by Lankau et al. (2012), this sentiment of "belonging" might sustain cooperation in a standard PG experiment. Given that inter-temporal transfers further weaken ties between subjects, our main behavioral hypothesis predicts a lower level of contribution in intertemporal settings compared to the intra-temporal setting $\left(\mathrm{H}_{1}\right)$.

What individuals have received in the past can establish a reference point that will affect contribution levels today (Bernheim, 1994; Ledyard, 1995; Alpizar et al., 2008). In the context of our inter-temporal experiment, this reference point rationale has one important implication. We thus hypothesize that providing subjects with information about the amount generated by the past investment in the $P G$ before they make their own contribution decisions should prompt them to contribute more, compared to the situation where they learn the amount received after they take their own decision $\left(\mathrm{H}_{2}\right)$.

The experiment was conducted in France at the LESSAC Experimental Lab in Dijon, the LEEM Experimental Lab of the University of Montpellier and the ESSEC Experimental Lab in Cergy, with a total of 320 participants. The subjects were recruited from the student population of the schools, who answered a call for paid decision experiments. The experiment builds on a between-subjects design, with seven treatments. One session typically lasted less than one hour, including instructions, verification questions and payment. 
At the beginning of the experiment, the subjects were randomly placed into groups of five anonymous players out of the total number of participants to a session. Instructions and decisions were computerized. ${ }^{7}$ All of the payoffs were denominated in Experimental Currency Units (ECU) and converted to euros at the end of the experiment at an exchange rate of 100 ECUs $=1$ euro. The subjects were informed that their reward from the experiment would depend on their own decision and the decisions of their partners. Individuals were asked to play a public goods game for 10 periods (rounds).

Both the control and the test treatments are based on the "stranger" PG design with the stated aim to contain individual reputation formation (Andreoni, 1988; Fehr and Gächter 2000). In this design, decision groups are randomly re-matched after each period within the set of participants to the experimental sessions. In the analysis by Fehr and Gächter (2000), the "stranger treatment" involved groups of 4 students out of 24 participants to the experimental sessions. They note that "in the partner-treatment the probability of being matched with the same three people in the next period is of 100 percent, whereas in the stranger treatment it is of less than 0.05 percent" (p.981). In our experiment, decision groups involved 5 subjects out of 15 or 20 participants to a session (the detail is provided in Table 1). ${ }^{8}$ As in the reference studies, participants might realize that they will play with some of the same partners in the future rounds. Thus, it must be acknowledged that, while limited, the scope for reciprocation among participants to one session still remains. A more powerful, but also more difficult to implement analysis would involve a larger number of participants per session.

\footnotetext{
${ }^{7}$ The computer program was developed in z-Tree (Fischbacher, 2007) by Delphine Dubart at the ESSEC Experimental Lab.

${ }^{8}$ The number of participants to the session was no common knowledge; students just could observe that a large group of students came to the Lab.
} 
The control treatment $\left(\mathbf{T}_{\mathbf{1}}\right)$ is referred to as the "intra-temporal setting". It is a standard linear, RPG experiment, where contributions and payoffs are provided at the same period $t$. At the beginning of each period, each subject receives 40 ECUs. Subjects can voluntarily contribute to the PG with an amount $v$, with $v \in[0 ; 40]$. One ECU invested provides all other members of the group with 0.5 ECU in the same period. One difference with a "standard" RPG is that in our experiment the individual gets no marginal benefit from his own investment. ${ }^{9}$ Additionally, the individual $i$ receives 0.5 ECU for any ECU invested in the PG by any of the other four players. In period $t$, the gain of one individual $i$ in a group of five is thus

$$
\pi_{i t}=40+R_{i t}^{t}-v_{i t}, \text { with } t=\{1 \ldots 10\},
$$

where $R_{i t}^{t}$, the income she/he receives from the four other contributors to the $\mathrm{PG}$, is given by

$$
R_{i t}^{t}=0.5 \sum_{j=1 ; j \neq i}^{4} v_{j t} .
$$

Subjects are informed about their total gain after each period. As already mentioned, after each round the groups are re-matched within the set of the participants to the experimental session.

Without a mechanism to coordinate their actions, selfish self-regarding agents would settle on the Nash equilibrium of the game; each subject would contribute nothing, and all of the subjects would end with 40 ECUs; this solution can be contrasted with the cooperative solution (each subject should invest all his endowment in the PG), and all of the subjects end the round with a payoff of 80 ECUs.

\footnotetext{
${ }^{9}$ This property facilitates the construction of comparable inter-temporal treatments.
} 
The other treatments $\left(\mathrm{T}_{2 \mathrm{a}}, \mathrm{T}_{2 \mathrm{~b}}, \mathrm{~T}_{2 \mathrm{c}}, \mathrm{T}_{3 \mathrm{a}}, \mathrm{T}_{3 \mathrm{~b}}, \mathrm{~T}_{3 \mathrm{c}}\right)$ are framed as the "inter-temporal setting". Treatments $T_{2}$ and $T_{3}$ differ with respect to the information structure: at a given round, subjects receive information on the amount of the benefit from past contributions to the PG after $\left(\mathrm{T}_{2}\right)$ or before $\left(\mathrm{T}_{3}\right)$ making their own decisions, i.e., they are either uninformed or informed. Subscripts $a, b$ and $c$ indicate variations of the endowment exogenously provided at the outset of the experiment $(\mathrm{t}=1)$.

In more detail, in any period $t$, subjects are assigned to a group of five persons; the groups are re-matched after each round within the set of participants to the experimental session. As in the intra-temporal setting, in each period, subjects can invest any amount $v \in[0 ; 40]$ in a PG. However, in this setting, one ECU invested at period $t$ by an individual $i$ will provide in the next period $(t+1)$ all other members of his new group with 0.5 ECU. Additionally, at time $t$, the individual $i$ benefits from the investment in PG made at the previous period $(t-1)$ by all the members of his current group. Subjects further receive a predetermined endowment of 40 ECUs at the beginning of each period.

Obviously, the first period $(t=1)$ cannot be defined in the same way as the subsequent periods because there is no "previous period". To launch the simulation, we thus created an "artificial previous period" ( $\mathrm{t}=0$ ) by providing subjects in the first period with an exogenous "transfer from the past" $A_{k}$ in addition to the 40 ECUs. We will study three distinct situations, corresponding to a low, an intermediate and a high transfer from the past, with $A_{a}=0, A_{b}=40$ and $A_{c}=80$. The low (respectively high) endowment could correspond to a group that played at $\mathrm{t}=0$ the (non-cooperative) Nash equilibrium strategy (respectively, the cooperative strategy).

We denoted the individual contribution to the PG by $v_{t}$. The gain of one individual $i$ at period $t$ can be written as:

$$
\pi_{i t}=40+R_{i t}^{t-1}-v_{i t}
$$


where the income he gets from the past contributions $R_{i t}^{t-1}$ is given by:

$$
R_{i t}^{t-1}= \begin{cases}A_{k}, \quad k=(a, b, c), & \text { for } t=1 \\ 0.5 \sum_{j=1 ; j \neq i}^{4} v_{j, t-1}, & \text { for } t=2,3, \ldots, 10\end{cases}
$$

At any round $t$ with $t>1$, if at the previous round ( $t$-1) individuals play the Nashequilibrium strategy and contribute nothing, then individuals will get at $t$ only the "regular" endowment of 40 ECUs. If all of the individuals contribute $v=40$ at $(t-1)$, at $t$ they will get 40 , plus four times 20 ECUs. Of course, this best possible outcome cannot be reached without a strong inter-temporal coordination mechanism.

We also introduce some variation in the information structure of the inter-temporal transfer game. In all $\mathrm{T}_{2 \mathrm{k}}$ treatments, the subjects are informed about the amount they receive from the past investment in public good after they make their own decision on how much to invest in the public good. Even during the first period $(t=1)$, the participants know that they will receive an extra amount but do not know how much. It is likely that they anchor their expectations around the known individual endowment of 40 ECUs. Subjects are also informed about their total gain after each period. In all $\mathrm{T}_{3 \mathrm{k}}$ treatments, the subjects are informed about the amount that they will receive from the past at the beginning of the period before making their own decision. In other words, when making their own investment decision, each subject knows how much they received from the past investment in the PG by other participants.

\section{Results}

In Table 1, the second column (respectively third) indicates the total number of participants in each treatment (the number of sessions). The rest of the table reports the 
average contribution for each treatment (lines) and rounds (columns, from t1 to t10). Figure 1 is the plot of the average contributions.

We obtain the standard result documented in the literature, i.e., the average amount invested in the public good declines over time in all treatments.

At $36 \%$ of the endowment, the first round average contribution in the control treatment (intra-temporal), is rather low. This is not surprising given that in this experiment individuals do not obtain any marginal benefit from contributing to the public good.

\begin{tabular}{|c|c|c|c|c|c|c|c|c|c|c|c|c|c|}
\hline & & $\mathbf{N}$ & $\mathbf{S}$ & t1 & t2 & t3 & t4 & t5 & t6 & t7 & t8 & t9 & t10 \\
\hline Control & $\mathrm{T} 1$ & 40 & 2 & 14,35 & 12,78 & 10,40 & 10,58 & 8,23 & 6,63 & 5,13 & 4,73 & 4,35 & 3,35 \\
\hline \multirow{3}{*}{ 音 } & T2_a & 60 & 3 & 16,25 & 14,77 & 17,77 & 17,10 & 17,85 & 14,82 & 16,72 & 12,67 & 11,80 & 10,45 \\
\hline & T2_b & 60 & 3 & 18,35 & 20,42 & 19,62 & 15,55 & 16,67 & 16,27 & 15,60 & 14,88 & 13,53 & 11,87 \\
\hline & $\mathrm{T} 2 \_\mathrm{c}$ & 60 & 4 & 18,07 & 23,42 & 21,92 & 19,83 & 13,17 & 15,52 & 14,57 & 12,52 & 12,53 & 9,33 \\
\hline \multirow{3}{*}{ 窇 } & T3_a & 40 & 2 & 17,43 & 19,58 & 21,05 & 19,38 & 17,45 & 19,08 & 18,25 & 17,58 & 12,83 & 13,73 \\
\hline & T3_b & 30 & 2 & 21,70 & 14,93 & 14,63 & 13,57 & 14,30 & 8,07 & 9,20 & 6,20 & 5,60 & 7,83 \\
\hline & T3_c & 30 & 2 & 23,10 & 21,90 & 21,03 & 19,20 & 16,83 & 17,63 & 16,27 & 17,43 & 17,90 & 12,40 \\
\hline
\end{tabular}

Legend. N: total number of participants per treatment; S: number of sessions; t1...t10 : the round.

Table 1. Average contributions per treatment and round

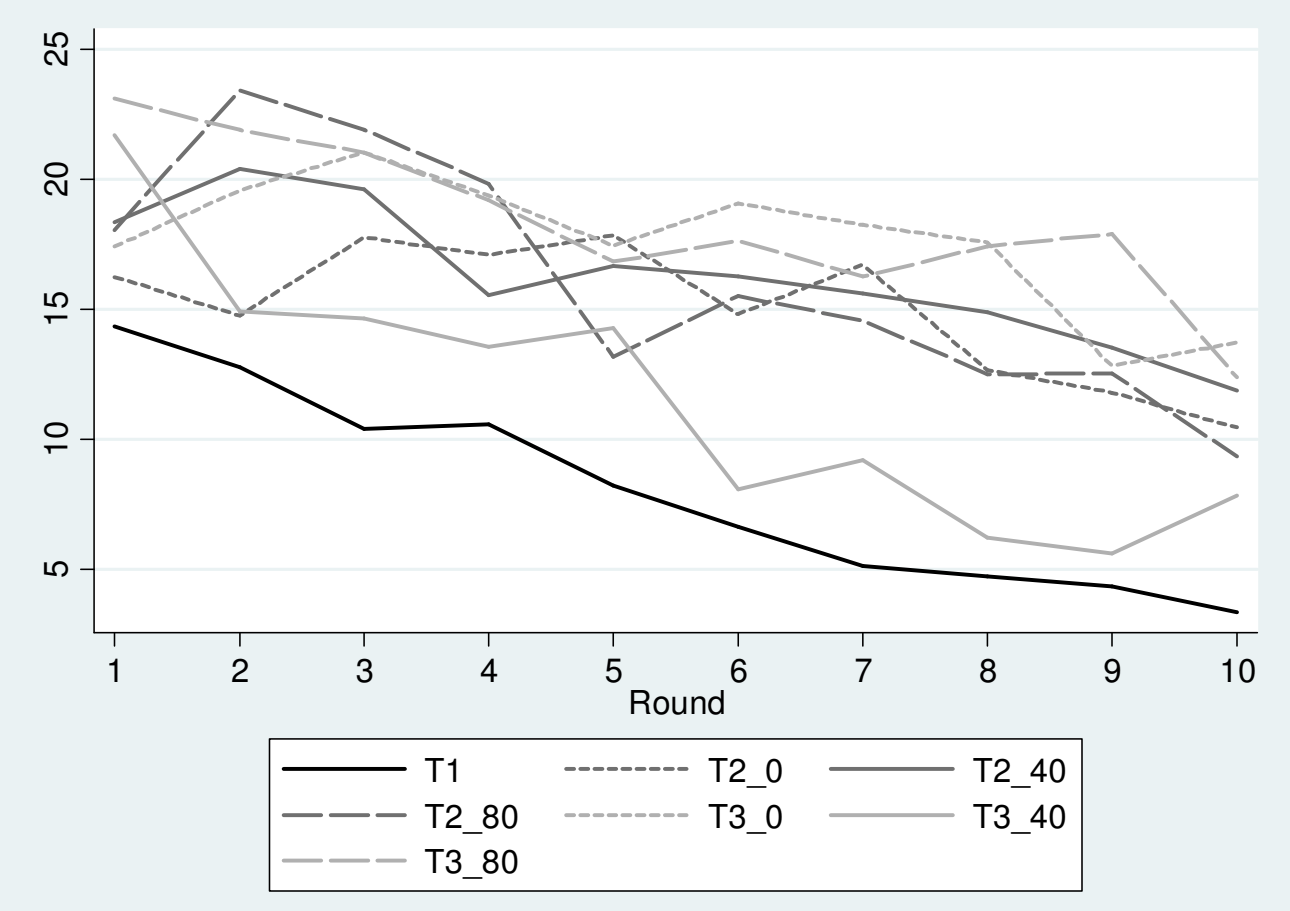


Figure 1. Average contributions per treatment and round

Figure 2 indicates the all-round average contribution to the PG, depending on the treatment. Closer inspection of the rough and average data put forward a first original result:

$\mathbf{R}_{\mathbf{1}}: H_{1}$ is not supported. Contributions to the $P G$ are systematically higher in the inter-temporal setting as compared to the intra-temporal setting.

While the all-round average contribution is $8.1 \mathrm{ECU}$ in $\mathrm{T} 1$, it is much higher in all other treatments (roughly the double), except in T3_40, where it is $43 \%$ higher nonetheless. A Tukey test shows that differences between T1 and all other treatments except T3_40 are statistically significant ( $\mathrm{p}$-value $<0.001 \%$ ). According to the same test, the difference between T1 and T3_40 is not statistically significant.

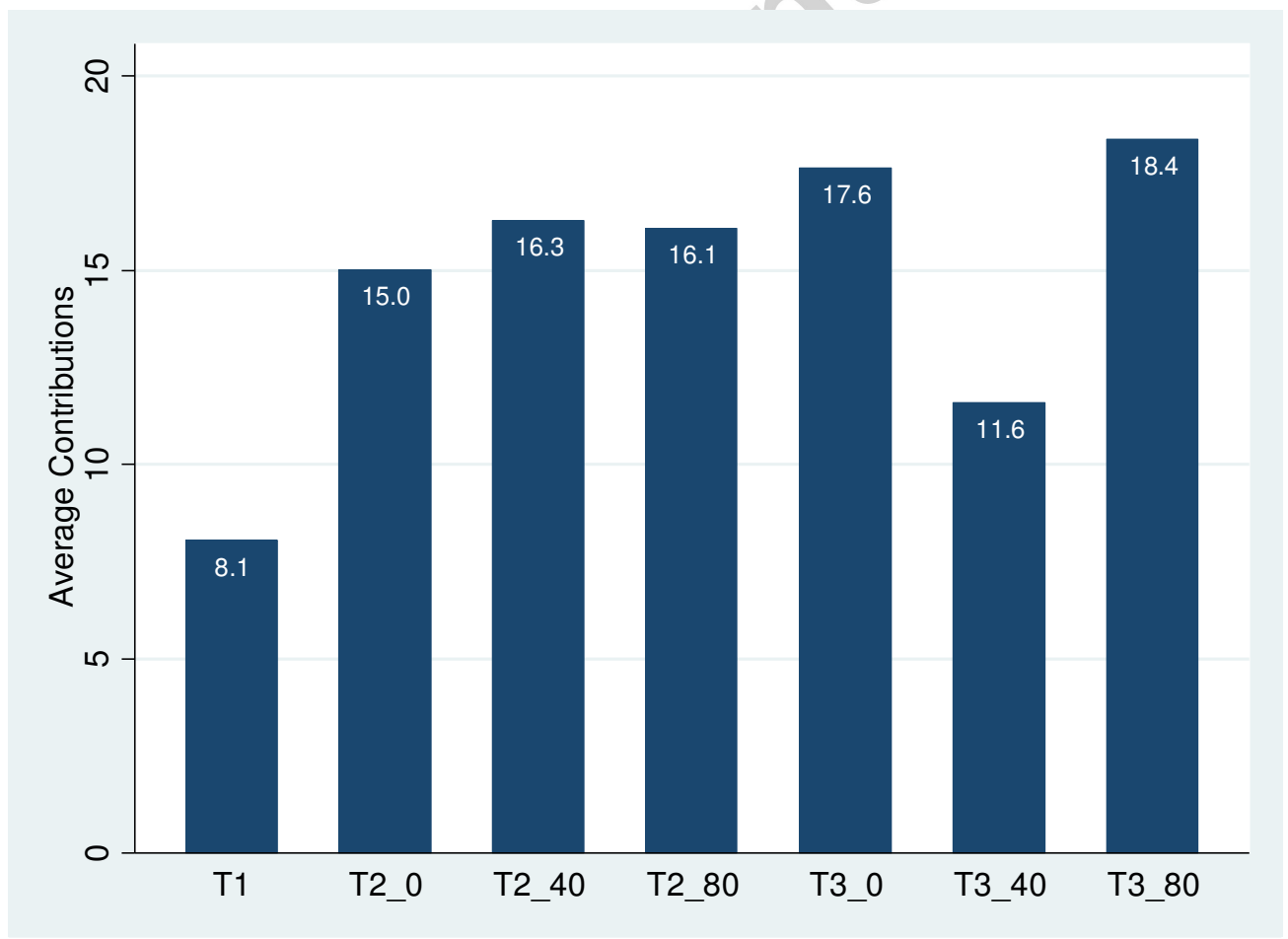

Figure 2. All-round average contributions depending on treatment

We can observe that: 
$\mathbf{R}_{\mathbf{2}}$ : Average maintenance rates in the three treatments are close to each other.

Indeed, we can define the maintenance rate of individual contributions as $\left(v_{\mathrm{t}} / v_{\mathrm{t}-1}\right)$ or how much of the contribution in period $t$-1 persists in period $t$. To determine the average maintenance rate, we run, for each treatment, the elementary regression:

$$
v_{i \mathrm{t}}=c+\mu v_{i t-1}+\varepsilon_{\mathrm{it}}
$$

where $v_{i t}$ is the contribution of an individual $i$ at round $t$.

Table 2 indicates the basic coefficients.

\begin{tabular}{lllllll}
\hline & T1 & \multicolumn{3}{c}{ T2 } & \multicolumn{3}{l}{ T3 } & \\
\hline Maintenance rate $\mu$ & $0.61^{* * *}$ & $(0.53-0.68)$ & $0.60^{* * *}$ & $(0.56-0.64)$ & $0.66^{* * *}$ & $(0.61-0.71)$ \\
\hline Constant & $2.11^{* * *}$ & $(1.15-3.11)$ & $5.83^{* * *}$ & $(5.03-6.64)$ & $4.64^{* * * *}$ & $(3.55-5.73)$ \\
\hline Number Obs. & 360 & & 1620 & & 900 & \\
\hline$R$-squared & 0.42 & & 0.35 & & 0.43 & \\
\hline
\end{tabular}

Random Effect GLS pooled data estimates. Between brackets: the 95\% confidence interval of the coefficient. Legend: $* * *$ significant at $1 \%$.

Table 2: Regression output (Dependent variable: individual contribution)

For the average maintenance rare $\mu$, the $95 \%$ confidence intervals for T1, T2 and T3 overlap, which yields the result R2: the difference between the average maintenance rates across treatments is not statistically significant.

However, constant terms are significantly higher in the inter-temporal treatments compared to the intra-temporal setting, which brings further support to R1.

We would now like to take the analysis of the inter-temporal context one step further and study whether what the individual receives as a benefit from a past investment in the PG 
has an impact on his own investment in the PG (tantamount to a benefit to individuals in $t+1$ ). As a comparison, we analyze in the standard intra-temporal context the impact of the previous benefits on the contemporary decision to contribute to the PG.

To reach this goal, we estimate a simple regression model with our panel data. The dependent variable is the voluntary contribution/investment in the PG of the individual $i$ at period $t, v_{\mathrm{it}}$. We are mainly interested in the impact of past benefits on current contributions. Thus, for $\mathrm{T} 2$ and $\mathrm{T} 3$, the key independent variable is the income the individual receives at time $t$ from the past investment in the public good, $R_{i t}^{t-1}$; notice that in T3 he observes it before he takes his own decision, while he observes it after he takes his own decision in T2. In the estimated equation for $\mathrm{T} 1 \mathrm{we}$ use as the main dependent variable $R_{i t-1}^{t-1}$, the income he received at time $(t-1)$ from the contribution to the public good at this period.

Furthermore, for our estimates of T2 and T3, we use situation (a) $\left(A_{k}=0\right)$ as the benchmark and create dummy variables for situations $(b)$ and $(c)$, denoted by SIT $b$ and SIT $c$.

The estimated equation is:

$$
v_{\mathrm{it}}=c+\beta_{1} \mathrm{ROUND}+\beta_{2} R_{i t-k}^{t-1}+\beta_{3} \mathrm{SITb}_{\mathrm{it}}+\beta_{4} \mathrm{SITc}_{\mathrm{it}}+u_{\mathrm{i}}+e_{\mathrm{it}}
$$

where $u_{\mathrm{i}}$ is the individual specific error term and $e_{\mathrm{it}}$ is the "standard" error term, as already mentioned, for $\mathrm{T} 2$ and $\mathrm{T} 3$ we set $\mathrm{k}=0$ and for $\mathrm{T} 1, \mathrm{k}=1$.

Table 3 provides the estimated model of Equation (1) with errors clustered per session (to allow for possible intra-group correlation of errors within a session).

\begin{tabular}{lllllll}
\hline & T1 & & T2 & T3 & \\
\hline C & $9.178^{* * *}$ & $(6.09-12.26)$ & $19.205^{* * *}$ & $(16.7-21.7)$ & $20.017^{* * *}$ & $(16.1-23.9)$ \\
\hline ROUND & $-0.760^{* * * *}$ & $(-0.90 ;-0.61)$ & $-0.872^{* * *}$ & $(-1.01 ;-0.72)$ & $-0.860^{* * *}$ & $(-2.07 ;-0.64)$ \\
\hline R & $0.160^{* * *}$ & $(-0.08 ;-0.23)$ & $0.022^{\text {ns }}$ & $0.072^{* * *}$ & $(0.03-0.10)$ \\
\hline SITb & -- & & $1.121^{\text {ns }}$ & $-5.533^{* * *}$ & $(-10.66 ;-0.4)$ \\
\hline SITc & -- & $0.843^{\text {ns }}$ & $-0.035^{\text {ns }}$ & \\
\hline
\end{tabular}




\begin{tabular}{llll}
\hline Nb. Obs & 360 & 1800 & 1000 \\
\hline R2-within & 0.27 & 0.09 & 0.10
\end{tabular}

Random Effects model with errors clustered at the session level. Between brackets: $95 \%$ confidence interval of coefficient. Legend: $* * * \mathrm{p}<0.01, * * \mathrm{p}<0.05$. $* \mathrm{p}<0.1$, ns- not significant.

Table 3. Estimation output of Equation 1. Dependent variable: individual contribution.

We can see that the trend coefficient $\beta_{1}$ is negative and highly significant: for all treatments, contributions decline over rounds, as they do in any standard PG game. Moreover, a comparison of the $95 \%$ confidence intervals for $\beta_{1}$ across treatments shows that there is no statistically significant difference between the three coefficients.

The constant term is much higher for the inter-temporal contexts (T2 and T3) compared to the intra-temporal one (T1), and the difference is statistically significant. This outcome further supports our result R1.

The analysis of the coefficient $\beta_{2}$ provides us with a third important result:

R3. When known in advance, past benefits from the public good provide individuals with a positive motivation to invest today.

Indeed, the coefficient $\beta_{2}$ is positive and statistically significant for T1 and T3. In T1, individuals know much they received in the previous round. In T3, when the individual benefits from a past investment in the PG, and knows it, he would also invest in a PG from whom a future group will benefit, as if individuals' are characterized by some form of intratemporal altruism nourished by the power of the example. When individuals do not know how much they receive from the past, this motivation disappears; $\beta_{2}$ is not significant in T2. In $\mathrm{T} 1$, the reference point effect also turns out to be significant.

As already mentioned, in the $\mathrm{T} 2$ and $\mathrm{T} 3$ treatments, we allow for different predetermined initial endowments for $t=1$. In line with the reference point rationale, we expect that high (respectively low) initial endowments will be associated with higher (lower) levels of contributions, at least during the early rounds. Most coefficients related to situation 
dummies are not significant, as if our limited variations in the initial endowment (Ak) have no significant impact on the subsequent decisions to contribute to the public good. We do not find a convincing explanation to the negative coefficient of SITb in the T3 treatment.

\section{Discussion and conclusion}

In the standard Repeated Public Goods game, contributions to the public good are redistributed within the active round among the anonymous members of the group. In this this paper, the analysis focuses on investment-type contributions to the PG, where benefits will reach a group of persons that will be constituted at a later time, and, at the decision time, individuals might benefit from investments in the PG made by other individuals in the past. Because decisions at one round carry their effects to the next round endowment, the problem can be referred to as a Dynamic Public Goods game.

Our brief survey of the literature on the repeated public goods experiments has shown that the PG game has challenged more than once the received ideas of economists. This paper goes in the same direction. Contrary to our main hypothesis, there is less cooperation in the intra-temporal treatment compared to the inter-temporal treatments. Matching a result firstly put forward by Cadigan et al. (2011), we find that subjects behave as if they feature some form of inter-temporal altruism; they appear to be concerned about the well-being of a group that will be formed at the next round, with strangers; this concern prompts them to contribute to the inter-temporal PG more than they contribute to a standard, intra-temporal PG. ${ }^{10}$

An explanation for this observed behavior can draw on the concept of "social contagion", as documented by Fowler and Christakis (2010), Suri and Watts (2011) and

\footnotetext{
${ }^{10}$ This finding can be related to the seemingly paradoxical finding by Andreoni (1988) and Palfrey and Prisbrey (1996) where participants in the Stranger treatment tend to contribute more than participants in the Partner treatment. Yet, as already mentioned, subsequent studies did not corroborate this result.
} 
Tsvetkova and Macy (2014). They use network-based experimental evidence to show that receiving help, or interacting with generous people increase the willingness of individuals to be generous toward the others (and vice-versa). It is possible that in our experiment the intertemporal mechanism enhances the perception of generosity, because in this context individuals who invest in the public good do it in a more "detached" way as compared to the intra-temporal context where the group cohesion is stronger. They thus appear to be more generous, as compared to an identical contribution in the intra-temporal context.

It is also possible that the intra-temporal setting activates more the dimension of an "economic computation" (own benefits), whereas inter-temporal settings activate more the "moral" dimension (related to others). Several papers indirectly argue that introducing private gain or losses activates economic computation rather than moral decisions, so we observe more egoistic and opportunistic behaviors (Tenbrunsel and Messick, 1999; Rogers, 2008). In the same vein, Kivetz and Tyler (2007) found that a distant (immediate) future is more likely to activate the idealistic (pragmatic) self and subsequent choices.

In our experiment, subjects contributed more on average when, at the moment of their own decision, they knew what they had received from the past. Knowing how much individuals have invested in the past in the PG can stimulate generosity, activate reciprocity or fix an anchor point.

While the stranger design of the experiment limits the scope for reciprocation among participants within an experimental session, it cannot rule it out completely, since the number of group members relative to the number of participants in a session is relatively large $(5 / 15$ and 5/20). Thus, with additional resources, it would be interesting to carry out the experiment within larger sets of participants in a session. It might also be interesting to implement a pure "inter-generational" experiment, where individuals play only once the inter-temporal PG game; in this case group reciprocation should play no role, and a higher contribution in the 
inter-temporal framework as compared to the intra-temporal frame can be interpreted as intertemporal altruism.

Finally, our paper might cast some light on factors that contribute to the success of environmental policies. A common prerequisite for addressing the challenge of sustainable development includes the obligations for current economic agents of not compromising the ability of subsequent individuals to meet their own needs. Our analysis shows that people may care more about individuals whom they may meet in the future than about current ones. ${ }^{11}$ In this case, environmental policies should be labeled as addressing future problems and individuals rather than contemporaneous issues. This mindset may be due to the fact that most individuals consider current problems as imminent and unsolvable, whereas, there is still time to find optimal solutions for future problems; therefore, people perceive their actions to be more useful. Additionally, to make these policies effective, general information should exist not only on their expected effects but also on what current individuals have inherited from the past. Rather than systematically pointing out environmental mistakes and failures, media and policymakers might spend also some efforts in communicating about the rising living standards in the last decades, and progresses obtained by society in preserving our environment.

\section{Acknowledgements}

This study benefited from the support by the research program Assessing and reducing environmental risks from pesticides funded by the French Ministry in charge of Ecology and the PARI grant from the Regional Council of Burgundy. R. Vranceanu carried out this research within the research program of the LABEX MME-DII. We would like to thank for

\footnotetext{
${ }^{11}$ Van der Heijden et al. (1998) observed a similar concern about the well-being of future generations in an environmental setup.
} 
their feedback anonymous referees, David Cooper, as well as participants to the London Experimental Workshop organized by the Middlesex University London on May 12-15, 2014, the Experimental Workshop in Aix-Marseille University on March 21-22, 2014, the regular research seminars at the Norwich University and ESC Dijon. We are indebted to Delphine Dubart, Dimitri Dubois and Guillermo Mateu for their technical assistance.

\section{References}

Alpizar, F., Carlsson, F., Johansson-Stenman, O., 2008, Anonymity, reciprocity, and conformity: Evidence from voluntary contributions to a national park in Costa Rica, Journal of Public Economics, 92 (5-6): 1047-1060.

Andreoni, J., 1988, Why free ride? Strategies and learning in public goods experiments, Journal of Public Economics, 37: 291-304.

Andreoni, J., 1989, Giving with impure altruism: Applications to charity and Ricardian equivalence, Journal of Political Economy, 97: 1447-58.

Andreoni, J., 1990, Impure altruism and donations to public goods: A theory of warmglow giving. Economic Journal, 100, (401), pp. 464-477.

Andreoni, J., 1995, Cooperation in public goods experiments: Kindness or confusion? American Economic Review, 85 (4): 891-904.

Andreoni, J., Petrie, R., 2004, Public goods experiments without confidentiality: a glimpse into fundraising, Journal of Public Economics, 88 (7-8): 1605-1623.

Bigoni, M., Suetens, S., 2012, Feedback and dynamics in public good experiments, Journal of Economic Behavior and Organization, 82 (1): 86-95. 
Bohm, P., 1972. Estimating demand for public goods: An experiment. European Economic Review, 3 (2), 111-130.

Bordignon, M., 1990, Was Kant right? Voluntary provision of public goods under the principle of unconditional commitment, Economic Notes, 3: 342-72.

Cadigan, J., Wayland, P.T., Schmitt, P., Swope, K., 2011, An experimental public goods game with carryover, Journal of Economic Behavior and Organization, 80: 523-531.

Camerer, C. F., Fehr, E., 2006. When does "economic man" dominate social behavior?, Science, 311 (5757), 47-52.

Carpenter, Jeffrey P., 2007, Punishing free-riders: How group size affects mutual monitoring and the provision of public goods. Games and Economic Behavior 60 (1): 31-51.

Chaudhuri, A., Graziano, S., Matra, P., 2006, Social learning and norms in an experimental public goods game with inter-generational advice, Review of Economic Studies, 73 (2): 357-380.

Chaudhuri, A., 2011, Sustaining cooperation in laboratory public goods experiments: A selective survey of the literature, Experimental Economics, 14 (1): 47-83.

Croson, R., 2007, Theories of commitment, altruism and reciprocity: Evidence from linear public goods games, Economic Inquiry, 45 (2): 199-216.

Croson, R., Fatas, E., Neugebauer, T., 2005, Reciprocity, matching and conditional cooperation in two public goods games. Economics Letters, 87, 1: 95-101.

Croson, R., 1996, Partners and strangers revisited. Economics Letters, 53, 1: 25-32.

Davis, D. D., Holt, C. A., 1993, Experimental Economics, Princeton Univerisity Press, Princeton.

Fehr, E., Gächter, S., 2000, Cooperation and punishment in public goods experiments, American Economic Review, 90 (4): 980-994. 
Fischbacher, U., Gächter, S., Fehr, E., 2001. Are people conditionally cooperative? Evidence from a public goods experiment, Economics Letters, 71 (3), 397-404.

Fischbacher, U., 2007, z-Tree: Zurich toolbox for ready-made economic experiments. Experimental economics 10 (2): 171-178.

Fischbacher, U., Gächter, S., 2010, Social preferences, beliefs, and the dynamics of free riding in public good experiments, American Economic Review, 100 (1), 541-556.

Fischer, M-E., Irlenbusch, B., and Sadrieh, A., 2004. An intergenerational common pool resource experiment. Journal of Environmental Economics and Management, 48 (2): 811-836.

Flanagin, A. J., Metzger, M. J., Pure, R., Markov, A., Hartsell, E., 2014. Mitigating risk in ecommerce transactions: perceptions of information credibility and the role of usergenerated ratings in product quality and purchase intention. Electronic Commerce Research, 14 (1): 1-23.

Fowler J. H., Christakis N. A., 2010, Cooperative behavior cascades in human social networks. Proceedings National Academy of Science USA, 107: 5334-5338.

Gordon, H. S., 1954. The economic theory of a common-property resource: The fishery. Journal of Political Economy: 62: 124-142.

Houser, D., Kurzban R., 2002, Revisiting kindness and confusion in public goods experiments. American Economic Review, , 92 (4): 1062-1069.

Holt, C., 2006, Markets, Games, and Strategic Behavior. Addison Wesley.

Hugh-Jones, D., Reinstein, D., 2011, The benefit of anonymity in public goods games, http://davidreinstein.files.wordpress.com/2011/05/secret_santa_experiment_may.pdf

Van der Heijden, E. C., Nelissen, J. H., Potters, J. J., Verbon, H. A. A., 1998, Transfers and the effect of monitoring in an overlapping-generations experiment. European Economic Review, 42 (7): 1363-1391. 
Isaac, R. M., Walker, J. M., 1988. Group size effects in public goods provision: The voluntary contributions mechanism. Quarterly Journal of Economics, 103: 179-199.

Isaac, R. M., Walker, J. M., \& Williams, A. W., 1994. Group size and the voluntary provision of public goods: experimental evidence utilizing large groups. Journal of Public Economics, 54 (1): 1-36.

Keser, C., and Van Winden, F., 2000, Conditional cooperation and voluntary contributions to public goods. Scandinavian Journal of Economics 102 (1): 23-39.

Kivetz, Y., Tyler, T.R., 2007, Tomorrow I'll be me: The effect of time perspective on the activation of idealistic versus pragmatic selves. Organizational Behavior and Human Decision Processes, 102: 193-211.

Lankau, M., Bicskei, M., Bizer, K., 2012, Cooperation preferences in the provision of public goods: An experimental study on the effects of social identity, Cege Discussion Papers 148, University of Göttingen. Available online at http://www. uni-goettingen. de/de/sh/60864. html.

Ledyard, J. O., 1995. Public good: A survey of experimental research. In The Handbook of Experimental Economics; Kagel, J.H., Roth, A.E., Eds.; Princeton University Press: Princeton, NJ, USA.

Levitt, S. D., List, J. A., 2007. What do laboratory experiments measuring social preferences reveal about the real world? Journal of Economic Perspectives, 21 (2): 153-174.

Masclet, D., Noussair, C., Villeval, M., Tucker S., 2003, Monetary and nonmonetary punishment in the voluntary contributions mechanism. American Economic Review, 93 (1): 366-380.

Marwell, G., Ames, R. E., 1979. Experiments on the provision of public goods. I. Resources, interest, group size, and the free-rider problem. American Journal of Sociology, 84, 6: 1335-1360. 
Nikiforakis, N., Normann, H. T., 2008. A comparative statics analysis of punishment in public-good experiments. Experimental Economics, 11 (4): 358-369.

Palfrey, T. R., Prisbrey, J. E. (1996). Altuism, reputation and noise in linear public goods experiments. Journal of Public Economics, 61 (3): 409-427.

Rege, M., Telle, K., 2004, The impact of social approval and framing on cooperation in public good situations, Journal of Public Economics, 88: 1625-1644.

Rogers, T., Bazerman, M. H., 2008, Future lock-in: Future implementation increases selection of should choices, Organizational Behavior and Human Decision Processes, 106 (1): $1-20$.

Sefton, M., Shupp, R., and Walker, J., 2007, The effects of rewards and sanctions in provision of public goods. Economic Inquiry, 45 (4): 671-690.

Smith, V. L., 1979. An experimental comparison of three public good decision mechanisms. Scandinavian Journal of Economics, 81: 198-215.

Smith, V. L., 1980. Experiments with a decentralized mechanism for public good decisions. American Economic Review, 70: 584-599.

Smith, V. L., Kehoe M., Cremer M., 1995, The private provision of public goods: Altruism and voluntary giving, Journal of Public Economics, 58: 107-26.

Sudgen, R., 1984, Reciprocity: The supply of public goods through voluntary contributions, Economic Journal, 94: 772-787.

Suri, S., Watts, D.J., 2011, Cooperation and contagion in web-based, networked public goods experiments. PLoS ONE 6: e16836. doi: 10.1371/journal.pone.0016836

Tenbrunsel, A.E., Messick, D.M., 1999, Sanctioning systems, decision frames, and cooperation, Administrative Science Quarterly, 44: 684-707.

Tsvetkova M., Macy, M.W., 2014, The social contagion of generosity. PLoS ONE 9(2): e87275. doi:10.1371/journal.pone.0087275. 
Zauberman, G., Lynch, J.G., 2005, Resource slack and propensity to discount delayed investments of time versus money, Journal of Experimental Psychology: General, 134 (1): 23-37.

Zelmer, J., 2003, Linear public goods experiments: A meta-analysis. Experimental Economics 6 (3): 299-310.

\section{Appendix :Instructions for Treatment T3 (all treatments use the same wording)} (Translated from French instructions)

Screen 1

Good morning.

Thank you for participating to this experiment. Please carefully read these instructions. Should you have any questions, please raise your hand and call the administrator.

Stay focused: do not use cellular phones or personal computers; otherwise, you may be excluded from the experiment.

Payoffs are denominated in Experimental Currency Units (ECU). At the end of the experiment, the ECU will be converted in euros at the exchange rates $100 \mathrm{ECU}=1$ euro. The final gain can reach approximately 10 euros.

Screen 2

You will play the same game for 10 rounds. You belong to a group of 5 anonymous players. The final payoff depends on your decisions and the decisions of the other players. The composition of the group changes every round. 
At the beginning of each round $t$, you will receive 40 ECUs. Each other member of your group will also receive 40 ECUs. In addition to this amount, you will receive a "transfer from the past". This amount depends on the rule defined in the next paragraph.

For each ECU that you invest in the public good during the round $t$, each other member of your new group, except you, will receive $0.5 \mathrm{ECU}$ in the round $t+1$ (each ECU you invest in the Public Good brings a total of 2 ECU to the four other members). In round $t$, you will benefit from the investment in public good of the members of your group in the previous round $t-1$. You can invest a maximum amount of 40 ECUs.

Thus your gain at each round is equal to 40 ECUs, less your investment, plus the total amount invested by the four other member of your group at round $(t-1)$ divided by 2 .

You will learn your gain for the round at the end of each round.

At the end of the experiment, the total game will be converted into euros and you will be paid anonymously and in cash.

Screen 3

To make sure that you understood the rules, please answer these questions:

1. The investment in $t$ contributes to the wealth of the group members
A. At time $t$
B. At time $\mathrm{t}-1$
C. At time $t+1$

2. During round $t$, each player in a group contributes 25 ECUs to the PG. During the previous period, the same players contributed 10 ECUs. The gain of a player for this round is:
A. $40-25+(25 \times 4) / 2$
B. $40+(25 * 5) / 2$
C. $40-25+(10 * 4) / 2$

Screen 4

Correct answers are $1 \mathrm{~B}$ and $2 \mathrm{C}$

Screens 5 and 6 - to be repeated ten times. 
Screen 5. Decision

Round \# 1 (... 10)

Your endowment is 40 ECUs

In Round 1 only: "Your bequest from the past is [A]" (depending on treatment, $\mathrm{A}=0,40,80)$.

In Rounds \# 2 to 10: "The investment of your group member at time ( $t$-1) brings you":

[R]

Your contribution to the PG for this round is [v] ECUs.

Screen 6. Results

Your endowment 40 ECUs.

Your investment in the PG is $[v]$ ECUs.

Round 1. "Your bequest from the past" is: [A] ECUs,

Rounds 2 to 10 . "The investment of your group member in round ( $t-1)$ brings you": [R]

Your gain for the round is $[y][=40-v+\mathrm{A}($ or $\mathrm{R})]$.

\section{Highlights}

The paper presents results from a dynamic public goods (DPG) experiment where the investment in the public good provides benefits to a group of individuals at a later stage.

In this inter-temporal context, contributions are higher than in the standard repeated public goods game with simultaneous contributions and benefits.

Individuals respond to information about what they received from past investments, by contributing more to the public good in the current period. 